\title{
"APOSENTADORIAS E PENSÕES" E DESIGUALDADE DA RENDA: UMA ANÁLISE PARA O BRASIL NO PERÍODO 1998-2003*
}

\author{
Carlos Roberto Ferreira ${ }^{* *}$
}

\section{Solange de Cássia Inforzato de Souza ${ }^{* * *}$}

\begin{abstract}
RESUMO Este trabalho tem como objetivo avaliar a contribuição do componente do rendimento domiciliar "aposentadorias e pensões" para a desigualdade da distribuição do rendimento domiciliar per capita no Brasil, nos meios rural e urbano, em 1998, 1999, 2001, 2002 e 2003. Para isso, utilizaram-se estratos de rendimento domiciliar per capita e a metodologia de decomposição do índice de Gini dos seguintes componentes: rendimento do trabalho principal, rendimento de outros trabalhos, aposentadorias e pensões, doações, rendimentos de aluguel e outros rendimentos (juros, dividendos etc.). Destaca-se, nos resultados, a substancial contribuição das aposentadorias e pensões para a desigualdade da distribuição da renda no Brasil. A estratificação dos rendimentos domiciliares permitiu a constatação de que, no Brasil rural, o percentual de domicílios e pessoas na população e os rendimentos total e das aposentadorias e pensões estão localizados nos estratos inferiores da renda.
\end{abstract}

Palavras-chave: previdência social; aposentadorias e pensões; distribuição de renda

Código JEL: D31; D63

\footnotetext{
* Artigo recebido em 21 de dezembro de 2005 e aprovado em 21 de novembro de 2007.

** Professor doutor do Departamento de Economia da Universidade Estadual de Londrina, e-mail: robert@uel.br

*** Professora doutora do Departamento de Economia da Universidade Estadual de Londrina, e-mail: soinfor@uel.br
} 
"RETIREMENTS AND PENSIONS" AND INEQUALITY OF THE INCOME: AN ANALYSIS FOR BRAZIL IN PERIOD 1998-2003

ABSTRACT This paper to analyze the contribution of the component of the household income "retirements and pensions" for the inequality of the per capita household income distribution in Brazil, in rural and urban areas, in 1998, 1999, 2001, 2002 and 2003. To that end, it was used per capita household income stratus and the Gini index decomposition methodology of the following components: main work income, other works incomes, retirements and pensions, donations, rent income and other incomes (interests, dividends etc.). The results showed the substantial contribution of the retirements and pensions for the inequality of the per capita household income distribution in Brazil. The household income stratification allowed showing that in Brazilian rural area, the percentage of households and people in the population and the total incomes and retirements and pensions incomes are located in inferior stratus of the income.

Key words: social security; retirements and pensions; income distribution 


\section{INTRODUÇÃO}

O debate sobre a previdência social brasileira intensificou-se a partir da segunda metade da década de 1990, em conseqüência dos seus significativos e crescentes resultados deficitários, particularmente evidenciados pelo comportamento do resultado financeiro do Regime Geral da Previdência Social (RGPS), para o setor privado (32 bilhões de reais em 2004), e do Regime Jurídico Único (RJU), para o funcionalismo federal (31,7 bilhões de reais em 2004). As despesas previdenciárias representaram, em 2004, 9,7\% do Produto Interno Bruto, e o total dos gastos sociais diretos do governo federal compreenderam 14,2\% do PIB. A desagregação dos dados indica que as despesas previdenciárias do RGPS significaram 7,35\% do PIB em 2004 (em 1998 esse número era de 5,63\%) e do RJU, 2,26\% (em 1998 o valor era 2,27\%). ${ }^{1}$

Os constrangimentos financeiros da previdência social são atribuídos a um conjunto de fatores que derivam do seu quadro institucional, gerencial e estrutural. O complexo institucional previdenciário está assentado no modelo de repartição simples, cuja lógica pressupõe que as contribuições pagas pelos trabalhadores ativos destinam-se a cobrir os gastos com benefícios dos inativos. O comportamento das variáveis demográficas, ${ }^{2}$ que denuncia aumento da expectativa de sobrevida da população e queda da fecundidade, as mudanças na composição do mercado de trabalho, com redução das contribuições previdenciárias, e a Constituição de 1988, que ampliou os benefícios, comprometem o sistema previdenciário, ao mesmo tempo em que o país revela, historicamente, expressiva concentração de renda.

A literatura aponta que o Brasil ocupa o oitavo lugar em concentração de renda no mundo, e ainda aproximadamente $47 \%$ da renda são apropriados pelos $10 \%$ mais ricos, enquanto os $50 \%$ mais pobres ficam com $12,7 \%$ da renda. Em 2001, as pessoas que compunham os 10\% mais ricos detinham uma renda 3,7 vezes maior do que toda a renda dos $50 \%$ mais pobres (Ferreira; Souza, 2004a). Outra importante verificação dos pesquisadores na área [(Ferreira; Souza, 2004a); Medeiros (2006); Barros et al. (2006)] é a de que o índice de Gini vem desacelerando no pós-1990, mais intensamente nos anos iniciais do século XXI.

Por outro lado, a previdência social do Brasil apresenta-se como um dos mais importantes instrumentos de política pública e base de sustentação da 
economia de um grande número de Municípios brasileiros de baixa renda, constituindo-se em substantivas possibilidades incrementais de renda domiciliar.

Este trabalho intenciona analisar a participação das aposentadorias e pensões no rendimento domiciliar per capita e a magnitude de sua contribuição para a concentração de renda no Brasil, nos meios rural e urbano, no período de 1998 a 2003, por meio da decomposição do índice de Gini e da estratificação do rendimento domiciliar per capita.

O trabalho segue, na seção 2, explicitando a base de dados e a metodologia aplicada na pesquisa. A terceira seção organiza a revisão de literatura sobre concentração de renda e previdência social no Brasil, seus antecedentes e experiência recente, para, na quarta seção, analisar os resultados da decomposição do índice de Gini e da estratificação da renda per capita. Ao final, considerações finais são apresentadas.

\section{METODOLOGIA}

\subsection{Base de dados}

O presente estudo tem por base as informações coletadas na Pesquisa Nacional por Amostra de Domicílios (PNAD), em 1998, 1999, 2001, 2002 e 2003. A PNAD tem periodicidade anual (interrompida em anos de censo demográfico), realizada por meio de uma amostra dos domicílios que abrange todo o país, exceto a área rural dos Estados da antiga região Norte (Acre, Amapá, Amazonas, Pará, Rondônia e Roraima). Para as pesquisas da década de 1990 e para as de 2001, 2002 e 2003, essa abrangência geográfica foi mantida, ou seja, a PNAD continuou a cobrir todo o país, com exceção da área rural dessas seis unidades da Federação. ${ }^{3}$

O procedimento metodológico adotado pelo IBGE implica que cada pessoa da amostra represente um determinado número de pessoas da população. Os dados individuais são fornecidos com o peso ou fator de expansão de cada indivíduo. Isso permite que os cálculos sejam elaborados ponderando-se cada observação pelo respectivo peso. Todos os cálculos, neste trabalho, foram feitos considerando o peso ou fator de expansão de cada domicílio da amostra da PNAD, fornecido pelo IBGE. 
As informações das PNADs são de boa qualidade, mas é preciso observar algumas características da natureza desses dados, as quais são restrições que precisam ser levadas em consideração na análise dos resultados, conforme alerta Hoffmann (1988 e 2002).

De acordo com as notas metodológicas do IBGE (2003), "considerou-se como rendimento mensal domiciliar a soma dos rendimentos mensais dos moradores do domicílio, exclusive os das pessoas cuja condição no domicílio fosse pensionista, empregado doméstico ou parente do empregado doméstico". Para se obter o rendimento domiciliar per capita, dividiu-se o rendimento mensal domiciliar pelo número de pessoas do domicílio, excluindo pensionistas, empregados domésticos e seus parentes.

Os componentes do rendimento domiciliar são os provenientes do trabalho principal, de outros trabalhos, de aposentadorias e pensões, dos aluguéis, doações, juros etc., apresentados para as pessoas de 10 anos ou mais de idade. Consideram-se rendimentos de trabalho os decorrentes dos pagamentos brutos mensais aos empregados, empregadores e conta própria, sejam advindos do trabalho principal ou dos demais trabalhos. O trabalho principal é o trabalho único que a pessoa de 10 anos ou mais de idade teve no período da pesquisa (semana de referência da PNAD), impondo-se outros critérios para casos especiais. Para pessoas com mais de um trabalho, o trabalho principal é aquele: (i) que a pessoa teve maior tempo de permanência no período de referência de 365 dias; (ii) em caso de igualdade no tempo de permanência prioriza-se o trabalho remunerado sobre o não remunerado; (iii) dentre os trabalhos remunerados com a mesma permanência no período de referência de 365 dias, prioriza-se aquele com maior número de horas semanais. O mesmo critério aplica-se quando a pessoa somente tiver trabalhos não remunerados e com a mesma permanência; e, em caso de igualdade nos critérios anteriores, prioriza-se aquele que normalmente proporcionava o maior rendimento.

Os rendimentos de aposentadorias e pensões são aqueles pagos pelo governo federal ou por instituto de previdência, entidades seguradoras ou fundos de pensão; e, finalmente, juros etc. são decorrentes de aplicações financeiras em ativos financeiros de renda fixa, caderneta de poupança e outros (IBGE, 2001). 


\subsection{Metodologia}

Os procedimentos da pesquisa contemplaram a estratificação do rendimento domiciliar per capita e a decomposição do índice de Gini para o Brasil, destacando a atividade agrícola e urbana na investigação nos anos 1998, 1999, 2001, 2002 e 2003. Essa decomposição da desigualdade considera os vários componentes que se somam para formar os rendimentos domiciliares: ${ }^{4}$ trabalho principal, outros trabalhos, aposentadorias e pensões, aluguéis, doações, juros etc.

Para a estratificação do rendimento domiciliar per capita consideram-se 11 estratos de renda, ressaltando-se que para o período analisado foram construídas tabelas que mostram a distribuição dos domicílios, do rendimento total e do rendimento domiciliar de aposentadorias e pensões.

O primeiro estrato inclui os domicílios cujo rendimento declarado é igual a zero; o segundo inclui os domicílios cujo rendimento declarado é igual até meio salário mínimo corrente ${ }^{5}(\mathrm{SM})$; o terceiro inclui rendimento entre meio SM e um SM; o quarto inclui rendimento entre um SM e um e meio SM; o quinto inclui rendimento entre um e meio SM e dois SM; o sexto inclui rendimento entre dois SM e dois e meio SM; o sétimo inclui rendimento entre dois e meio SM e três SM; o oitavo inclui rendimento entre três SM e quatro SM; o nono inclui rendimento entre quatro e oito SM; o décimo inclui rendimento entre oito e $15 \mathrm{SM}$; e o décimo primeiro inclui rendimentos maiores que $15 \mathrm{SM}$. Ressalte-se que os domicílios com rendimentos não declarados foram eliminados da análise.

Na decomposição do índice de Gini ${ }^{6}$ a literatura de Pyatt, Chen e Fei (1980) mostra como o índice de Gini pode ser decomposto quando se considera a divisão do rendimento analisado em vários componentes. ${ }^{7}$

Seja $z_{i}$ o rendimento da $i$-ésima pessoa. Neste trabalho considera-se o rendimento domiciliar per capita, considerando que ele é o resultado da soma de $k$ parcelas:

$$
z_{i}=\sum_{h=1}^{k} z_{h i}
$$

Vamos admitir que os rendimentos $z_{i}$ estão ordenados de maneira que $z_{1}$ $\leq z_{2} \leq \ldots \leq z_{n}$, sendo $n$ o tamanho da população. Então $i$ é a posição de ordem do rendimento $z_{i}$. 
Pode-se verificar que o índice de Gini $(G)$ da distribuição de $z_{i}$ é

$$
G=\frac{2}{n \mu} \operatorname{cov}\left(z_{i}, i\right)
$$

onde $\mu$ é a média dos $z_{i}$.

Pyatt, Chen e Fei (1980) definem a razão de concentração do componente $z_{h i}$ como

$$
C_{h}=\frac{2}{n \mu h} \operatorname{cov}\left(z_{h i}, i\right)
$$

onde $\mu_{h}$ é a média dos $z_{h i}$.

A participação do $h$-ésimo componente no rendimento total é

$$
\phi_{h}=\frac{\mu_{h}}{\mu}
$$

Pode-se deduzir que

$$
G=\sum_{h=1}^{k} \phi_{h} C_{h}
$$

Vamos indicar por $i_{h}$ os números de ordem associados aos valores de $z_{h i}$ se eles fossem colocados em ordem crescente. Os $i_{h}$, da mesma maneira que $i$, variam de 1 a $n$. Note-se, entretanto, que, para determinando $z_{h i}$, o respectivo valor de $i$ (o número de ordem do correspondente $z_{i}$ ) não vai, em geral, coincidir com $i_{h}$ (a posição desse $z_{h i}$ na ordenação dos valores desse componente). Analogamente a (2), o índice de Gini de $z_{h i}$ é

$$
G_{h}=\frac{2}{n \mu_{h}} \operatorname{cov}\left(z_{h i}, i_{h}\right)
$$

De (3) e (6) obtém-se

$$
R_{h}=\frac{C_{h}}{G_{h}}=\frac{\operatorname{cov}\left(z_{h i}, i\right)}{\operatorname{cov}\left(z_{h i}, i_{h}\right)}
$$

Pyatt, Chen e Fei denominaram $R_{h}$ "razão de correlação de ordem".

De (5) e (7) segue-se que 


$$
G=\sum_{h=1}^{k} \phi_{h} R_{h} G_{h}
$$

Essa expressão mostra como o índice de Gini de $z_{i}$ está associado com os índices de Gini de cada componente.

Note-se, na expressão (5), que se todas as razões de concentração $C_{h}$ tivessem o mesmo valor, esse seria, também, o valor de $G$. Dessa forma, podese considerar que um componente $z_{h i}$ contribui para aumentar a desigualdade (medida pelo índice de Gini) quando $C_{h}>G$.

\section{DISTRIBUIÇÃO DE RENDA E A PREVIDÊNCIA SOCIAL NO BRASIL}

\subsection{Antecedentes}

As relações entre a concentração da renda e as políticas econômica e social formam um conjunto de grande complexidade que tem estimulado diversos pesquisadores.

No âmbito da previdência social, sua origem remonta à criação das Caixas de Aposentadorias e Pensões (CAPs) por categoria ocupacional ou empresa - o marco é a lei Elói Chaves, de 1923, sendo as CAPs referentes aos empregados de empresas ferroviárias, dos portuários e marítimos, e outros, de modo que em 1921 já haviam 183 CAPs no país.

Após a experiência dos anos 1920, as Caixas são substituídas pelos IAPs (Institutos de Aposentadorias e Pensões), sob o regime de capitalização, que incorporavam setores urbanos organizados dos trabalhadores, segundo a categoria profissional, centralizados no governo federal. ${ }^{8}$

Embora tendo centralidade na agenda política da previdência social, a proteção social no Brasil não logrou êxito no sentido de universalização dos benefícios até a primeira metade dos anos 1960. Por outro lado, foram importantes para a base de acumulação baseada no desenvolvimento industrial pós-1930, seja em sua fase de industrialização restringida (1930-1955), seja em sua fase de boom (1956-1961).

O período pós-1964 foi, para o sistema de proteção e para a previdência social, um marco de rompimento com o padrão histórico, reformando a previdência social sob a perspectiva da unificação e universalização dos benefícios, financiada por contribuições sociais dos trabalhadores e gerida pelo regime de repartição simples. ${ }^{9}$ No período da imaginação reformista 
(1964-1967), na economia brasileira foram gestados os formatos institucional e financeiro da política social brasileira. Na previdência social destacase, sob resistência de alguns institutos, a unificação dos IAPs, materializada no INPS (Instituto Nacional de Previdência Social), em 1967.

Além dos condicionantes políticos, os fatores econômicos que influenciaram a nova concepção de proteção e previdência social foram o próprio contexto econômico e a política econômica do PAEG (Plano de Ação Econômica do Governo), centrada na estabilidade de preços e reformas institucionais, que visavam a ampliar o sistema de financiamento da economia e reduzir gastos sociais públicos, que obstruíam a industrialização pesada no país e pressionavam o orçamento fiscal.

A estratégia econômica adotada influenciou os rumos da reforma previdenciária entre 1964 e 1967, pois, ao conflitar com os objetivos do PAEG, a crise financeira do complexo previdenciário, agravada nos anos 1960, passou a ser também uma questão econômica, justificando intervenções saneadoras. Em parte, a unificação dos institutos previdenciários foi impulsionada por objetivos racionalizadores, visando ao estabelecimento de critérios gerais de economicidade (Braga; Paula, apud Fagnani, 1997).

A fase de crescimento econômico de 1968-1973 impulsionou a consolidação da unificação previdenciária e o fortalecimento de sua base financeira. Há uma expansão da cobertura, sublinhando, em 1971, o Prorural, financiado pelo Funrural, que incluiu trabalhadores rurais e seus dependentes como beneficiários da previdência social.

A partir de 1974, diante da reversão da tendência de crescimento econômico, implementou-se a racionalização dos gastos sociais, ao mesmo tempo em que se objetivava enfatizar a face redistributiva dos programas sociais. Tal racionalidade operacionalizou o Sinpas (Sistema Nacional de Previdência e Assistência Social), aglutinando as agências de arrecadação (Iapas), de concessão de benefícios (INPS) e serviços médicos (Inamps). A cobertura continuou se expandindo, cobrindo, na década de 1970, em termos previdenciários, 52\% da PEA (5\% do PIB), de acordo com Draibe (1993).

No que se refere à distribuição de renda, somente a partir do Censo Demográfico de 1960 é que passaram a existir dados censitários adequados para estudos sobre o assunto no Brasil. Os diversos trabalhos sobre distribuição da renda mostram que o Brasil tinha experimentado entre 1960 e 1970 um aumento na concentração de renda sem precedentes em relação 
aos países para os quais existe documentação estatística (Bonelli; Ramos, 1993, p. 77).

A origem da má distribuição da renda, segundo Romão (1991), é o resultado da inserção histórica da economia brasileira no processo de expansão do capitalismo industrial, particularmente na forma diferenciada pela qual a apropriação de tecnologia se processou entre os diversos setores da economia. Isso gerou uma estrutura bastante heterogênea do aparato produtivo nacional e, em conseqüência, do esquema distributivo de renda. De acordo com Hoffmann e Duarte (1972), quando se comparam as distribuições da renda em 1960 e 1970, verifica-se que ela é sensivelmente mais desigual no setor urbano que no setor primário, e o aumento no grau de concentração da distribuição da renda foi mais acentuado nas regiões mais industrializadas.

Os trabalhos de Hoffmann (1983) e Bonelli e Ramos (1993), entre outros, mostram que a distribuição da renda na década de 1970 tornou-se ainda mais concentrada, embora o aumento da desigualdade tenha sido menor que nos anos 1960 .

Hoffmann e Kageyama (1986) notam que a mudança na distribuição da renda na década de 1970 teve características distintas daquelas observadas na década de 1960. Nesse trabalho eles utilizaram como unidades de análise as famílias e as pessoas economicamente ativas. Para a década de 1960, essas três unidades de análise apresentaram como resultado um acentuado aumento na desigualdade. Na década de 1970, a desigualdade entre pessoas economicamente ativas cresce, mas de forma menos intensa que na década de 1960. Quando se consideram as famílias como unidade de análise, a desigualdade sofre um pequeno decréscimo. Entre 1970 e 1980, o processo de concentração de renda foi mais intenso no setor agropecuário do que nos setores urbanos, como conseqüência da modernização da agricultura, ao contrário do ocorrido na década anterior, para todas as regiões do país.

De acordo com os autores, as reduções nos índices de desigualdade entre 1970 e 1980 foram muito pequenas, da ordem de 3\% a 4\%. Em 1980, cada membro da unidade familiar de metade da população brasileira recebia menos de meio salário por mês para sobreviver, enquanto pouco mais de um milhão de pessoas (o 1\% mais rico) dispunha de quase 18 salários mínimos mensais per capita. 
A par disso, na década de 1980, o complexo previdenciário foi atingido pelas condições econômicas desfavoráveis, tais como a crise financeira internacional, o ajuste recessivo e as pressões populares por medidas redistributivas. Assim, combinaram-se, medidas destinadas a reduzir os gastos com benefícios, ao mesmo tempo em que se ampliavam as carências sociais decorrentes da crise econômica e emergência de temáticas sociais pela democratização.

Fagnani (1997) escreve que esse período foi o do esgotamento de uma estratégia que se iniciou em 1964 e cujos traços estruturais presentes, com maior ou menor força, foram a regressividade dos mecanismos de financiamento (a base de financiamento da previdência era o FPAS - Fundo de Previdência e Assistência Social) e o Estado se desresponsabilizando financeiramente; a centralização do processo decisório no governo federal (o Sinpas foi exemplo disso), impulsionada pelas reformas institucionais de 1964-1967; a permeabilidade aos interesses privados e o uso clientelista (o autor cita as indicações dos agentes para o Funrural e o aumento do número de benefícios concedidos em anos eleitorais); o aumento quantitativo da oferta de serviços sociais (entre 1971 e 1980, o número de segurados inativos urbanos passou de 2,3 milhões para 5,3 milhões); e o reduzido caráter redistributivo. Na previdência social, apreende-se este último aspecto pelo baixo valor dos benefícios, condicionamento do acesso ao benefício, limitada cobertura do trabalhador rural e privilégios para categorias especiais.

Hoffmann (1995) estuda a distribuição das famílias de acordo com o rendimento familiar no Brasil, de 1979 a 1990, observando a variação do valor real dos rendimentos médio e mediano provocada pelos efeitos da recessão de 1981 a 1984 e a recuperação em 1985 e 1986. De acordo com pesquisador, o crescimento dos rendimentos médio e mediano em 1986 se deve à coincidência entre o mês de referência da PNAD (setembro) e o período de auge dos efeitos benéficos do Plano Cruzado. Além disso, setembro de 1986 foi um período eleitoral, o mesmo ocorrendo com setembro de 1989, em que se observa o rendimento médio obtido a partir dos dados da PNAD relativamente elevado.

Verifica-se também que a desigualdade da distribuição da renda entre famílias foi relativamente estável no período 1979-1986, e há uma pequena redução da desigualdade em 1986. No período entre 1979 e 1987, o índice de 
Gini, Theil e a percentagem da renda apropriada pelos $10 \%$ mais ricos permaneceram dentro de um mesmo patamar, sofrendo pequenas variações.

A década de 1980 teve, pois, um perfil distributivo semelhante ao da década de 1970. O processo de concentração se agravou principalmente a partir da segunda metade da década, com a elevação da taxa de inflação, sucessivos planos de ajustes e as políticas salariais adotadas no período (Lacerda, 1994). O país chegou à última década do século XX ostentando um dos maiores índices de desigualdade da distribuição da renda em nível mundial. A interpretação dos fatores determinantes da variação do grau de concentração de renda deu origem a controvérsias, gerando debates sobre as razões que deram origem ao aumento da concentração de renda.

Com o advento da Nova República, há um movimento mais intenso no sistema de proteção. Sob o conceito de seguridade social foram ampliadas as concepções relativas à previdência, saúde e assistência social, seu modo de financiamento, redefinição dos planos de benefícios e formas de organização que apontam para o aumento na universalização do acesso, dos direitos e da descentralização das ações. No caso da previdência, o texto constitucional de 1988 contribuiu para a igualização dos benefícios dos trabalhadores urbanos e rurais e alteração de valores, apresentando resultados financeiros satisfatórios até 1994. A partir de 1995, as contas da previdência social passaram a ser deficitárias, conforme mostra a tabela 1.

\subsection{A experiência recente}

A década de 1990 iniciou-se com a política social perdendo a centralidade, dentro de um contexto econômico e político desfavorável à sua consecução. ${ }^{10}$

Se na década anterior e nos primeiros anos da década de 1990, o volume arrecadado pelas contribuições de empregados e empregadores permitia financiar a totalidade dos benefícios previdenciários, a situação se agravou no pós-1994. Podem-se apontar os determinantes dessa situação. De acordo

Tabela 1: Evolução do déficit da previdência social, \% do PIB, de 1995 a 2004

\begin{tabular}{lcccccccccc}
\hline Deficit & \multicolumn{10}{c}{ Anos } \\
\cline { 2 - 12 } & 1995 & 1996 & 1997 & 1998 & 1999 & 2000 & 2001 & 2002 & 2003 & 2004 \\
\hline Total & 2,8 & 3,8 & 3,7 & 4,4 & 4,7 & 4,8 & 5,3 & 5,2 & 5,6 & 5,3 \\
\hline Fonte: Giambiagi et al. (2004). & & & & & & & & &
\end{tabular}


com Marques (1997), houve aumento dos gastos com benefícios de 1992 para 1993 da ordem de 24,4\%, e em relação a 1988 foi de 70,4\%. Concorreram para isso, primeiramente, a existência de demanda reprimida por conta da expectativa de que a Constituição viesse a melhorar as condições de acesso e valor dos benefícios, a imposição da justiça brasileira para o pagamento de direitos atrasados, o represamento de pagamentos entre janeiro e outubro de 1992, e, já em 1994, uma ação de antecipação da demanda diante das possíveis mudanças do governo em relação à previdência social.

Em segundo lugar, há de se verificar que os ingressos de novos contribuintes na década de 1970 refletiram um incremento de beneficiários nos anos 1990, ao mesmo tempo em que nesta última década desestruturava-se o mercado de trabalho com reduzida capacidade contributiva. Ramos e Reis (1997) e Ramos e Britto (2004) evidenciam o crescimento da informalidade, que passou de $40 \%$, em 1991, para $51 \%$ da população economicamente ativa (PEA), em meados de 2000, baseados nos dados da pesquisa mensal de emprego (PME) do IBGE. O fraco desempenho do emprego assalariado com carteira e o aumento dos empregadores e dos trabalhadores por conta própria sem contribuição para a previdência são fatos que colaboram para intensificar a problemática vivenciada na década de 1990.

Além dos problemas expostos, as modificações na estrutura demográfica e o envelhecimento da população tornam-se incompatíveis com as condições de acesso à aposentadoria. Os impactos da dinâmica demográfica com respeito à previdência social refletem-se tanto nas despesas com benefícios quanto no lado das receitas. Para manter o equilíbrio no sistema de repartição simples, o elemento fundamental, considerando-se somente as variáveis demográficas, é a estrutura etária da população em cada momento, pois é ela que define a relação entre beneficiários e contribuintes (Stephanes, 1999).

Segundo Stephanes (1999), a relação de contribuintes ativos por beneficiário na década de 1950 era de oito, enquanto para as décadas de 1970 e 1980 essa relação foi de 4,2 e 3,2, respectivamente. Para Ornélas (2002), essa mesma relação caiu de 2,4, em 1991, para 1,7, em 1997. Essa queda implicou sucessivos aumentos das alíquotas de contribuição, redução no valor real dos benefícios e utilização de receita de impostos para cobrir o déficit da previdência. E mais, Ornélas e Vieira (2002) destacam que a base de contribuintes da previdência no Brasil esteve sempre abaixo do seu potencial. Em 
1997, cerca de 62\% da população ocupada não contribuíam para o Regime Geral de Previdência Social (RGPS) e 56\% dela não contribuíam para nenhum tipo de previdência.

Pode-se sintetizar que a proposta da estabilidade e retomada do crescimento para a promoção do bem-estar social nos anos 1990 mostrou-se contraditória, fragilizando as políticas sociais, já que desorganizou o mercado de trabalho brasileiro e conduziu ao crescimento da dívida pública interna, de R $\$ 60$ bilhões, em 1994, para mais de R\$ 320 bilhões, em 1998, chegando em 2005 a R\$ 1 trilhão.

As políticas passivas e ativas do mercado de trabalho, como as do seguro-desemprego (Azeredo, 1998), qualificação profissional (Souza, 2002), intermediação de mão-de-obra e geração de emprego e renda (Valle, 1998), apresentaram-se insuficientes diante da magnitude da desorganização, precariedade e flexibilidade do mercado de trabalho, uma das faces mais contundentes da exclusão econômica no país (Singer, 1999). Ademais, afeta financeiramente as fontes fiscais e contribuições sociais, fontes de recursos para a política social vinculada ao mercado formal de trabalho.

Inauguram-se, diante desse panorama, as reformas da previdência, com a EC no 20 e a Lei 9.717/1998, que buscavam atingir o regime de previdência do setor público, especialmente. Em 1998, as despesas com esse regime totalizavam R $\$ 20,9$ bilhões, sendo a contribuição dos servidores de R 2,6 bilhões, cobertas pelo Tesouro. No âmbito do regime geral da previdência social, os desequilíbrios financeiros foram evidentes no pós-1994, colaborando para isso a estagnação econômica e as mudanças no mercado de trabalho. Daí que entre 1995 e 1998 viabilizaram-se outras medidas, como a substituição do

Tabela 2: Gastos sociais e despesa com benefícios do governo federal, em percentual do PIB, de 1995 a 2004

\begin{tabular}{lrrrrrrrrrr}
\hline Despesas & \multicolumn{10}{c}{ Anos } \\
\cline { 2 - 10 } & 1995 & 1996 & 1997 & 1998 & 1999 & 2000 & 2001 & 2002 & 2003 & 2004 \\
\hline Área social & 11,8 & 11,5 & 11,4 & 11,9 & 12,6 & 12,7 & 13,4 & 13,7 & 13,8 & 14,2 \\
\hline Índice 1 & 99,0 & 96,0 & 95,0 & 100,0 & 105,9 & 106,7 & 112,6 & 115,1 & 116,0 & 119,0 \\
\hline Benefícios & 7,3 & 7,5 & 7,4 & 8,0 & 8,3 & 8,2 & 8,7 & 8,9 & 9,5 & 9,7 \\
\hline Índice 2 & 91,3 & 93,8 & 92,5 & 100,0 & 102,5 & 102,5 & 108,7 & 111,2 & 118,7 & 121,2 \\
\hline Fonte: Brasil (2005). & & & & & & & & &
\end{tabular}

Nota: As linhas referentes aos índices 1 e 2 referem-se aos comportamentos das despesas da área social e dos benefícios previdenciários, com base em 1998. 
tempo de serviço por tempo de contribuição, o que limita o acesso das camadas mais desfavorecidas diante das características do mercado de trabalho dos anos 1990. Diante do comprometimento do ajuste fiscal e da própria estabilização, evidencia-se a urgência das reformas da previdência, favorecidas pelo ambiente de desconforto em relação ao Estado e à esfera pública. ${ }^{11}$

A agenda de reformas da previdência seguiu para os anos iniciais do século XXI, agora também sustentadas na amplitude dos gastos sociais e na participação das despesas da previdência nos gastos sociais totais do governo federal, conforme pode-se observar na tabela 2. O qüinqüênio 1998-2003 identificou um crescimento de $18,7 \%$ nas despesas com os benefícios previdenciários, enquanto o crescimento com gastos sociais do governo federal cresceram $16 \%$.

Como descrito, a conjugação da problemática da previdência social e da desigualdade de renda no Brasil lança para a agenda de pesquisa a necessidade de se analisar a contribuição dos rendimentos das aposentadorias e pensões para a concentração de renda. É o que se faz a seguir.

\section{RESULTADOS DA PESQUISA}

\subsection{Estratos de rendimento domiciliar per capita}

As tabelas 3 a 5 mostram a distribuição percentual dos domicílios particulares permanentes e das pessoas nesses estratos, o percentual do rendimento total e do rendimento de aposentadorias e pensões para o Brasil, assim como as suas esferas urbana e rural, nos anos 1998, 1999, 2001, 2002 e 2003.

A tabela indica que a maior concentração percentual de domicílios na população do Brasil está no estrato 3 , enquanto a maior concentração percentual de pessoas na população está no estrato 2 . Ambos estão concentrados nos estratos inferiores da distribuição, ou seja, nos estratos em que estão localizados os relativamente pobres. $\mathrm{O}$ mesmo não acontece com a concentração percentual do rendimento total e do rendimento domiciliar de aposentadorias e pensões, que ocorrem no estrato 9 , em que estão localizados os relativamente ricos.

No Brasil rural, a maior concentração percentual de domicílios e pessoas na população está no estrato 2 , e ainda, $87,7 \%$ dos domicílios obtiveram rendimentos de até um salário mínimo e meio em 2003. O percentual de rendimento total e do rendimento domiciliar de aposentadorias e pensões também está em maior proporção no estrato 3 , ou seja, em que estão locali- 


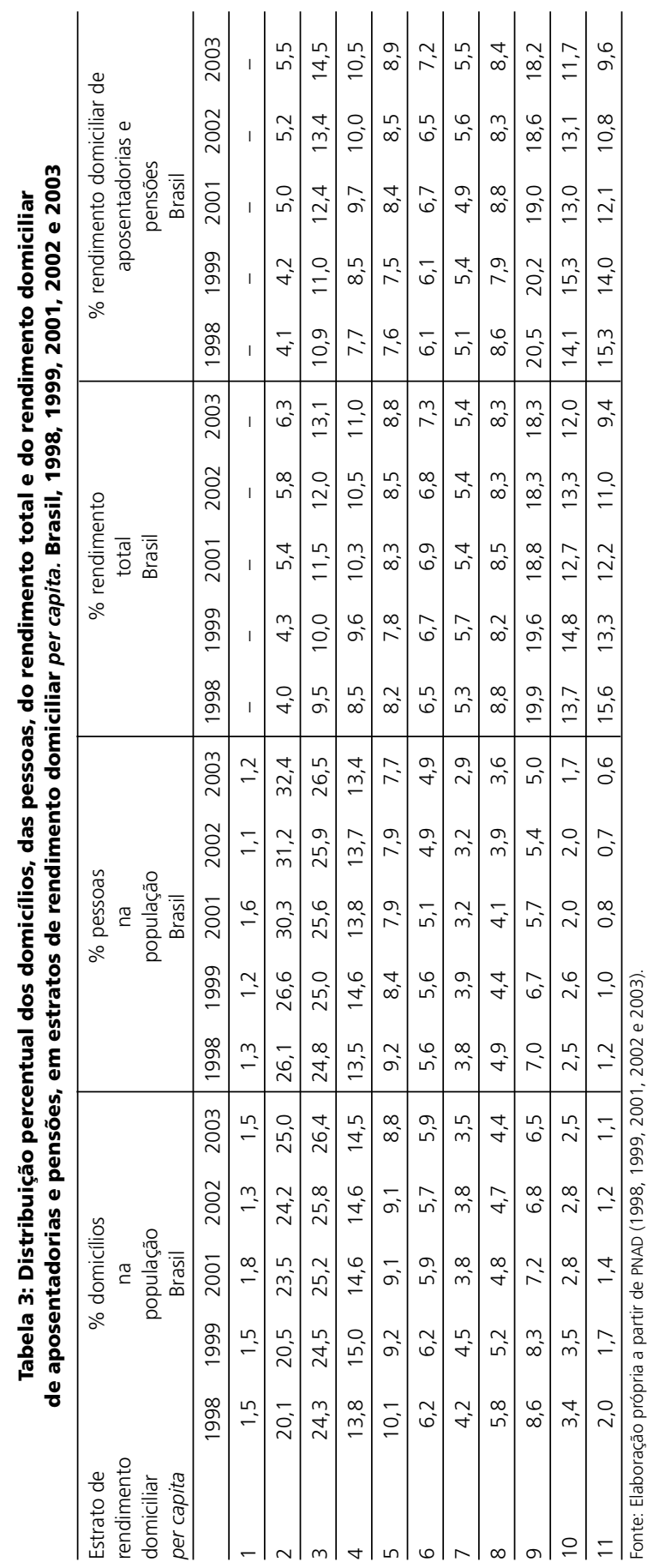




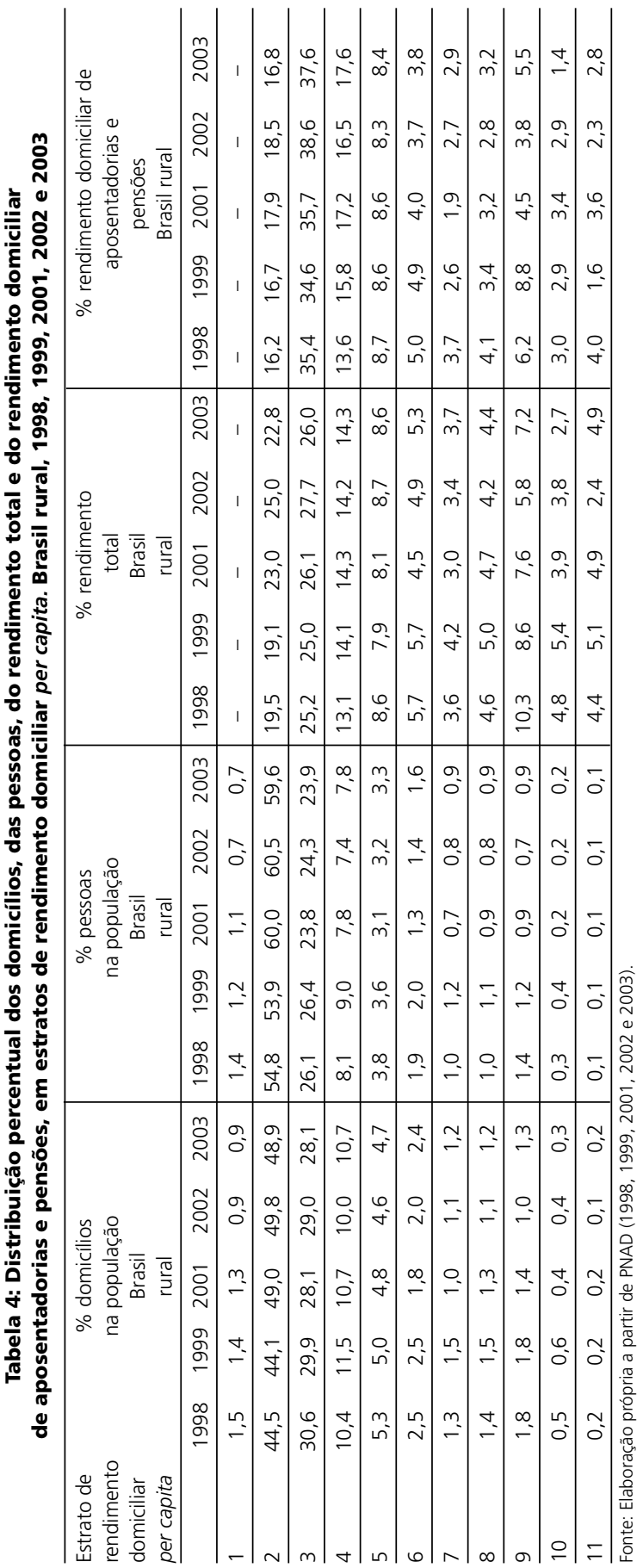




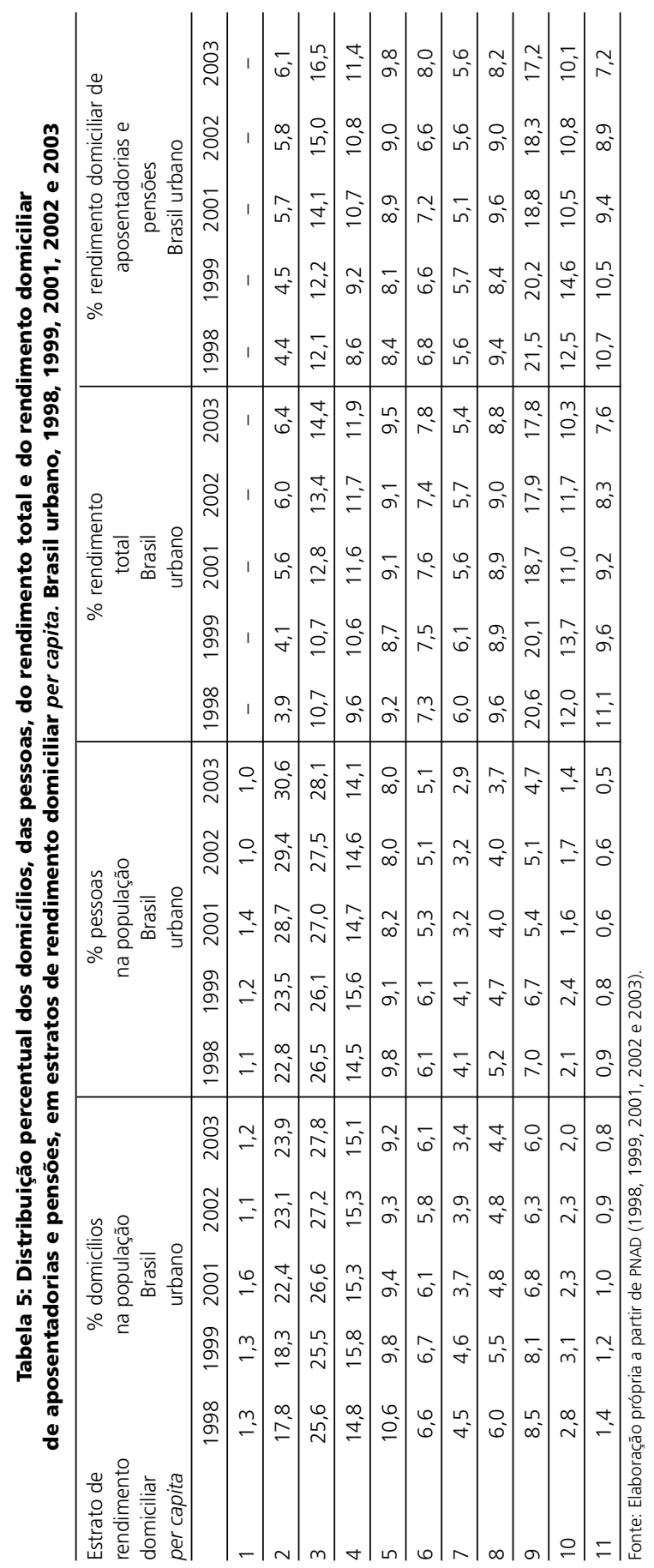


zados os relativamente pobres. Se considerarmos o intervalo até um salário mínimo e meio, os dados indicam que a concentração dos rendimentos domiciliares das aposentadorias e pensões é alta e crescente, já que, em 2003, $72 \%$ desse rendimento estavam nesses estratos, contra 65,2\% de 1998 .

A tabela 5 evidencia que o estrato 3 contém o maior percentual de domicílios na população do Brasil urbano, embora o percentual de domicílios na população do Brasil urbano com até meio salário mínimo também esteja aumentando (estrato 2). Observa-se que o percentual de pessoas na população está crescendo nos estratos 2 e 3, ou seja, nos relativamente pobres.

Com relação ao percentual do rendimento total e rendimento domiciliar de aposentadorias e pensões, a maior concentração, ainda que decrescente, está no estrato 9 . O estrato 9 também apresenta concentração de rendimentos decrescente. Por outro lado, o estrato 3 revela um crescimento na concentração de rendimentos, indicando que está havendo um aumento no número de domicílios e pessoas que recebem aposentadorias e pensões de até um salário mínimo.

Através da estratificação do percentual do rendimento total e do rendimento domiciliar de aposentadorias e pensões, nota-se que tais rendimentos estão sempre concentrados, seja nos estratos inferiores, para o meio rural, seja nos estratos superiores, para os demais.

Nota-se que no Brasil e no Brasil urbano os estratos que concentram o maior número de domicílios não detêm o maior percentual de renda total e rendimento de aposentadorias e pensões. A renda total está concentrada nos estratos superiores, em que estão os relativamente ricos. Esse comportamento é diferente na esfera rural brasileira, pois no Brasil rural apresenta-se o maior número de domicílios e renda total nos estratos inferiores, em que estão os relativamente pobres.

Analisando somente os rendimentos de aposentadorias e pensões, observa-se que é nos estratos superiores (relativamente ricos) que existe a predominância desse tipo de rendimento. Essa relação é diferenciada se analisarmos o Brasil rural, em que tal rendimento está concentrado nos estratos inferiores. De forma geral, verifica-se um descompasso entre os estratos que concentram mais domicílios e, conseqüentemente, mais pessoas e a distribuição do rendimento total e das aposentadorias e pensões. Especificamente, para o meio rural estratificado, essa tendência não se verifica. 


\subsection{Resultados da decomposição do índice de Gini}

A tabela 6 mostra os resultados da decomposição do índice de Gini da distribuição do rendimento domiciliar per capita no Brasil, para os anos 1998, 1999, 2001, 2002 e 2003, considerando-se seis componentes: rendimento do trabalho principal das pessoas ocupadas; rendimento de outros trabalhos; aposentadorias e pensões; doações; aluguéis; e uma parcela constituída por juros, dividendos e outros rendimentos. Em 1998, apenas o rendimento do trabalho principal e as doações têm razão de concentração $\left(C_{h}\right)$ menor do que o índice de Gini global. Embora a razão de concentração das doações seja a mais baixa para os cinco anos analisados, ela ainda é positiva, indicando que o valor das doações per capita tende a crescer com o rendimento domiciliar per capita.

Nota-se também que os rendimentos do trabalho principal, para o período analisado, devido à sua grande participação no total, dão origem à maior parcela do índice de Gini.

Entre os demais componentes do rendimento, as aposentadorias e pensões têm papel de destaque. Em 1998, representavam 16,7\% do rendimento total, dando origem ao mesmo percentual do índice de Gini. Em 2003, significaram $19,8 \%$ do rendimento total, participando com $20,3 \%$ do índice de Gini, evidenciando um crescimento de 3,1\% na participação da renda total

Tabela 6: Decomposição do índice de Gini do rendimento domiciliar per capita no Brasil em 1998, 1999, 2001, 2002 e 2003: participação do componente no rendimento total $\left(\phi_{h}\right)$, razão de concentração $\left(C_{h}\right)$ e parcela do componente no índice de Gini geral $\left(\phi_{h} C_{h}\right)$

Brasil

Componente 199819992001200220031998199920012002200319981999200120022003

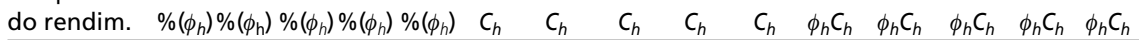
Trabalho

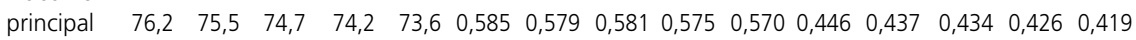

Outros

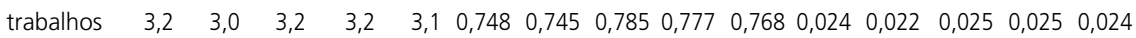

Apos.

$\begin{array}{llllllllllllllll}\text { e pensões } & 16,7 & 17,8 & 18,5 & 18,7 & 19,8 & 0,599 & 0,603 & 0,603 & 0,592 & 0,592 & 0,100 & 0,107 & 0,112 & 0,111 & 0,118\end{array}$

\begin{tabular}{llllllllllllllll}
\hline Aluguéis & 2,4 & 2,2 & 1,9 & 1,9 & 1,7 & 0,803 & 0,803 & 0,797 & 0,803 & 0,801 & 0,019 & 0,018 & 0,015 & 0,015 & 0,014
\end{tabular}

\begin{tabular}{llllllllllllllll}
\hline Doações & 0,7 & 0,7 & 0,7 & 0,8 & 0,7 & 0,413 & 0,354 & 0,395 & 0,429 & 0,403 & 0,003 & 0,002 & 0,003 & 0,003 & 0,003
\end{tabular}

\begin{tabular}{llllllllllllllll}
\hline Juros etc. & 0,9 & 0,8 & 0,9 & 1,3 & 1,0 & 0,764 & 0,695 & 0,539 & 0,512 & 0,338 & 0,007 & 0,006 & 0,005 & 0,007 & 0,004
\end{tabular}

Total $\quad 100,0 \quad 100,0 \quad 100,0 \quad 100,0 \quad 100,0 \quad 0,598 \quad 0,592 \quad 0,594 \quad 0,587 \quad 0,581 \quad 0,598 * 0,592 * 0,594 * 0,587 * 0,581$ *

Fonte: Elaboração própria a partir de PNAD (1998, 1999, 2001, 2002 e 2003).

* Valores correspondentes ao índice de Gini. 
e 3,6\% na formação do índice de Gini global. A esses incrementos observados pelas aposentadorias e pensões contrapõe um movimento de decréscimo do componente trabalho principal no total dos rendimentos e na formação do índice de Gini.

Nas áreas urbanas (tabela 7), a participação do rendimento das aposentadorias e pensões também é crescente. Em 1998, esse rendimento representou $16,7 \%$ do rendimento total e originou $16,6 \%$ do índice de Gini. Em 2003 , houve um crescimento de sua participação, passando para 18,8\% do rendimento total, contribuindo com 18,7\% do índice de Gini. No período, o crescimento da participação das aposentadorias e pensões na renda total e na formação do índice de Gini foi de 2,1\%. Observa-se que a razão de concentração de aposentadorias e pensões para esses anos 1999, 2001 e 2002 é superior ao índice de Gini total.

O papel das aposentadorias e pensões é mais destacado na formação do rendimento domiciliar per capita no Brasil rural, conforme pode-se ver na tabela 8. Em 1998, o rendimento de aposentadorias e pensões representou $18,1 \%$ do rendimento total e originou 18,6\% do índice de Gini. Em 2001, esse rendimento representou $21,7 \%$, e em 2003, sua participação foi de 23,1\% do rendimento total e originou 25\% do índice de Gini. De 1998 a 2003 as aposentadorias e pensões aumentaram em $5 \%$ a sua participação no

Tabela 7: Decomposição do índice de Gini do rendimento domiciliar per capita no Brasil urbano, em 1998, 1999, 2001, 2002 e 2003: participação do componente no rendimento total $\left(\phi_{h}\right)$, razão de concentração $\left(C_{h}\right)$ e parcela do componente no índice de Gini geral $\left(\phi_{h} C_{h}\right)$

Brasil urbano

Componente 199819992001200220031998199920012002200319981999200120022003

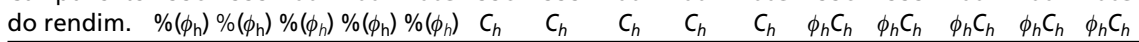
Trabalho

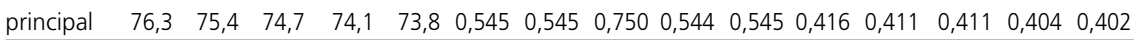

Outros

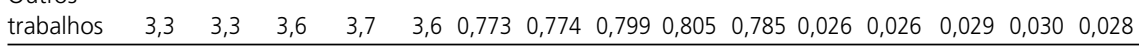

Apos.

$\begin{array}{llllllllllllllll}\text { e pensões } & 16,7 & 17,5 & 18,1 & 18,3 & 18,8 & 0,559 & 0,562 & 0,567 & 0,561 & 0,553 & 0,093 & 0,098 & 0,103 & 0,103 & 0,104\end{array}$

\begin{tabular}{llllllllllllllll}
\hline Aluguéis & 2,4 & 2,4 & 2,2 & 2,1 & 1,9 & 0,783 & 0,796 & 0,794 & 0,796 & 0,791 & 0,019 & 0,019 & 0,017 & 0,017 & 0,015
\end{tabular}

\begin{tabular}{llllllllllllllll}
\hline Doações & 0,7 & 0,7 & 0,7 & 0,8 & 0,8 & 0,300 & 0,242 & 0,328 & 0,375 & 0,333 & 0,002 & 0,002 & 0,002 & 0,003 & 0,003
\end{tabular}

\begin{tabular}{llllllllllllllll}
\hline Juros etc. & 0,6 & 0,6 & 0,7 & 1,0 & 1,1 & 0,660 & 0,610 & 0,454 & 0,381 & 0,337 & 0,004 & 0,004 & 0,003 & 0,004 & 0,004
\end{tabular}

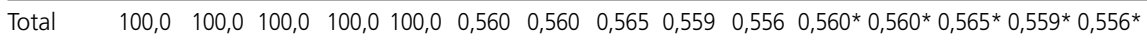

Fonte: Elaboração própria a partir de PNAD (1998, 1999, 2001, 2002 e 2003).

* Valores correspondentes ao índice de Gini. 
rendimento total, enquanto para o Brasil esse aumento foi de 3,1\%. Com relação à participação das aposentadorias e pensões no índice de Gini total, houve um aumento de 6,4\% no Brasil rural e 3,6\% no Brasil. As razões de concentração para os cinco anos analisados são maiores do que o índice de Gini, indicando que as aposentadorias e pensões contribuem para a concentração de renda no meio rural do Brasil.

Apesar de o índice de Gini apontar valores menores para o Brasil rural do que para o Brasil urbano, o que significa que a concentração da renda no espaço rural é menor do que no urbano, as razões de concentração das aposentadorias e pensões são maiores na região rural, assim como também o são as parcelas do componente do índice de Gini total.

No espaço rural do Brasil identifica-se mais fortemente a participação das aposentadorias e pensões no rendimento total per capita dos domicílios, cujo valor está, em média, 20,6\% no qüinqüênio estudado, sendo para o Brasil 18,3\%. Ademais, a taxa de crescimento da participação desse componente no rendimento total foi de $27,6 \%$ de 1998 a 2003 no setor rural, enquanto no Brasil como um todo esse incremento foi de $18,6 \%$.

A crescente relevância dos benefícios previdenciários rurais é dos elementos que indicam semelhanças aos mais diversos países, que, segundo

\footnotetext{
Tabela 8: Decomposição do índice de Gini do rendimento domiciliar per capita no Brasil rural, em 1998, 1999, 2001, 2002 e 2003: participação do componente no rendimento total $\left(\phi_{h}\right)$, razão de concentração $\left(C_{h}\right)$ e parcela do componente no índice de Gini geral $\left(\phi_{h} C_{h}\right)$
}

Brasil rural

Componente 199819992001200220031998199920012002200319981999200120022003

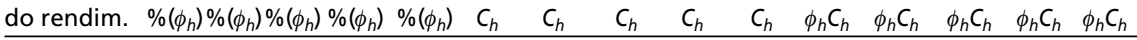
Trabalho

$\begin{array}{llllllllllllllll}\text { principal } & 74,5 & 75,4 & 70,3 & 69,4 & 69,9 & 0,540 & 0,535 & 0,529 & 0,501 & 0,532 & 0,402 & 0,403 & 0,372 & 0,348 & 0,372\end{array}$

Outros

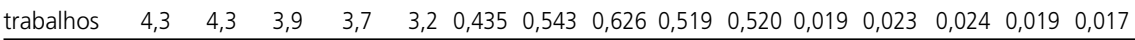

Apos.

$\begin{array}{llllllllllllllll}\text { e pensões } & 18,1 & 17,4 & 21,7 & 22,7 & 23,1 & 0,560 & 0,542 & 0,586 & 0,566 & 0,578 & 0,101 & 0,094 & 0,127 & 0,128 & 0,133\end{array}$

\begin{tabular}{llllllllllllllll}
\hline Aluguéis & 1,4 & 1,4 & 1,6 & 1,1 & 1,2 & 0,877 & 0,851 & 0,904 & 0,884 & 0,890 & 0,012 & 0,012 & 0,014 & 0,010 & 0,011
\end{tabular}

\begin{tabular}{llllllllllllllll}
\hline Doações & 0,7 & 0,7 & 0,5 & 0,6 & 0,5 & 0,239 & 0,171 & 0,162 & 0,322 & 0,130 & 0,002 & 0,001 & 0,001 & 0,002 & 0,001
\end{tabular}

\begin{tabular}{llllllllllllllll}
\hline Juros etc. & 1,0 & 1,0 & 2,0 & 2,5 & 2,2 & 0,578 & 0,507 & 0,093 & 0,116 & 0,030 & 0,006 & 0,005 & 0,002 & 0,003 & 0,001
\end{tabular}

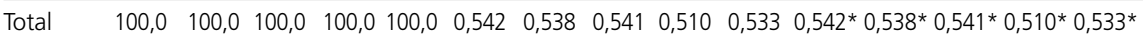

Fonte: Elaboração própria a partir de PNAD (1998, 1999, 2001, 2002 e 2003).

* Valores correspondentes ao índice de Gini. 
Schwarzer (2000), deverá se aprofundar em decorrência do processo de envelhecimento da população e da restrição dos mercados de trabalho, particularmente do trabalho rural.

\section{CONSIDERAÇÕES FINAIS}

A distribuição do rendimento domiciliar per capita em 11 estratos mostrou que, no Brasil como um todo e no meio urbano, o maior percentual de domicílios e de pessoas recebe até um salário mínimo e meio, e, portanto, faz parte dos relativamente pobres, enquanto o maior percentual do rendimento total e do rendimento de aposentadorias e pensões está concentrado nos estratos superiores, em que estão localizados os relativamente ricos. No meio rural, constatou-se que o maior percentual de domicílios e de pessoas também recebe até um salário mínimo e meio, mas fica com os maiores percentuais do rendimento total e do rendimento domiciliar de aposentadorias e pensões.

$\mathrm{Na}$ decomposição do rendimento domiciliar per capita nos seus vários componentes, que permite avaliar a magnitude da sua contribuição para a desigualdade no país, observa-se que é crescente o percentual de rendimento domiciliar médio no Brasil advindo das aposentadorias e pensões. Em 1998, o rendimento das aposentadorias e pensões participava com 16,7\% da renda total, e em 2003 esse valor foi de 19,8\%.

No tocante ao rendimento domiciliar per capita, no Brasil rural verificase que a participação do rendimento das aposentadorias e pensões no rendimento total é ainda mais acentuado, crescendo 5\%. Esse crescimento na parcela de rendimento das aposentadorias e pensões é bem-vindo ao setor rural, que de forma geral é carente de recursos.

No espaço rural, a razão de concentração para o Brasil rural, no período analisado, é maior que o valor do índice de Gini global, o que indica que nesse âmbito há contribuição das aposentadorias para a desigualdade de renda. Por outro lado, a estratificação dos rendimentos domiciliares permitiu a constatação de que, para todas as regiões rurais analisadas, a concentração dos rendimentos total e de aposentadorias e pensões localiza-se nos estratos inferiores de renda. 


\section{NOTAS}

1. Ver Brasil (2005).

2. As informações são as de que, no ano 2002, o país tinha 16.022.231 pessoas com mais de 60 anos, 9,3\% da população. Desse montante, 12.445 .563 são aposentados ou pensionistas, 77,7\% do total de idosos (IBGE, 2004). A participação das pessoas com mais de 60 anos na população brasileira mais do que dobrou no último meio século, passando de 4\%, em 1940, para 8\%, em 1996. Estima-se que em 2020 aproximadamente $15 \%$ da população serão compostos por idosos (Camarano, 2002).

3. Em 2004, a PNAD foi implantada na área rural de Rondônia, Acre, Amazonas, Roraima, Pará e Amapá, e alcançou a cobertura completa do território nacional.

4. Um exemplo numérico de decomposição pode ser encontrado em Ferreira (2003).

5. Em termos nominais, o valor do salário mínimo em 1998, 1999, 2001, 2002 e 2003 foi de $\mathrm{R} \$ 130,00, \mathrm{R} \$ 136,00, \mathrm{R} \$ 180,00, \mathrm{R} \$ 200,00$ e $\mathrm{R} \$ 240,00$, respectivamente.

6. O índice de Gini é uma das principais medidas de desigualdade. Para detalhes, veja Hoffmann (1998).

7. Ver, também, Shorrocks (1982). No Brasil, essa metodologia já foi utilizada por Ferreira (2003), Neder (2001) e Mariano e Lima (1998).

8. Entre 1933 e 1945, foram criados sete IAPs - marítimos, industriários, transportes de carga, bancários, comerciários, estivas e servidores do Estado.

9. No modelo de repartição simples, as contribuições dos atuais trabalhadores financiam as aposentadorias dos inativos, e as próximas gerações vão financiar os benefícios dos que estão contribuindo.

10. Marques (1997) escreve que no próprio momento de promulgação da Constituição, o então presidente da República alertava, em cadeia nacional, que os novos direitos sociais e previdenciários inviabilizariam o sistema — várias medidas provisórias foram baixadas para dificultar esses direitos.

11. Oliveira (1998) mostra como operou o deslocamento da esfera pública para a privada, ao que ele denomina despublicização - movimento contrário ao ocorrido entre 1930 e 1980.

\section{REFERÊNCIAS BIBLIOGRÁFICAS}

AMSBERG, J. V.; LANJOUW, P.; NEAD, K. A focalização do gasto social sobre a pobreza no Brasil. In: HENRIQUES, R. (Org.). Desigualdade e pobreza no Brasil. Rio de Janeiro: IPEA, 2000 .

AZEREDO, B. Políticas públicas de emprego: a experiência brasileira. São Paulo: ABET, 1998.

BARROS, R.; CARVALHO, M.; FRANCO, S.; MENDONÇA, R. Uma análise das principais causas da queda recente na desigualdade de renda brasileira. Rio de Janeiro: IPEA, 2006.

BARROS, R. P.; FOGUEL, M. N. Focalização dos gastos públicos sociais e erradicação da pobreza no Brasil. In: HENRIQUES, R. (Org.). Desigualdade e pobreza no Brasil. Rio de Janeiro: IPEA, 2000. cap. 25, p. 719-739. 
BONELLI, R.; RAMOS, L. Distribuição de renda no Brasil: avaliação das tendências de longo prazo e mudanças na desigualdade desde meados dos anos 70. Revista de Economia Política, v. 13, n. 2, p. 76-97, abr./jun. 1993.

BRASIL. Ministério da Fazenda. Secretaria de Política Econômica. Orçamento social do governo federal: 2001-2004. Brasília, 2005.

CAMARANO, A. A. Envelhecimento da população brasileira: uma contribuição demográfica. Texto para Discussão, Rio de Janeiro: IPEA, n. 858, 26 p., 2002.

DELGADO, G.C.; CARDOSO JUNIOR, J.C. O idoso e a previdência rural no Brasil: a experiência recente da universalização. In: CAMARANO, A. A. (Org.). Muito além dos 60: os novos idosos brasileiros. Rio de Janeiro: IPEA, 1999. cap. 11, p. 319-343.

DRAIBE, S. M. Qualidade de vida e reformas de programas sociais: o Brasil no cenário latinoamericano. Lua Nova, n. 31, 1993.

FAGNANI, E. Política social e pactos conservadores no Brasil: 1964/92. Economia e Sociedade, Campinas, n. 8, p. 183-238, jun. 1997.

FERREIRA, C. R. Participação das aposentadorias e pensões na desigualdade da distribuição da renda no Brasil no período de 1981 a 2001. 136 p. (Tese de Doutorado), Escola Superior de Agricultura "Luiz de Queiroz", Universidade de São Paulo, Piracicaba, 2003.

FERREIRA, C. R.; SOUZA, S. C. I. A contribuição das parcelas do rendimento domiciliar per capita para a desigualdade no Brasil. Londrina: UEL, 2004a. (mimeo.)

—. Previdência social e desigualdade: a participação das aposentadorias e pensões na distribuição da renda no Brasil - 1981 a 2001. Londrina: UEL, 2004b. (mimeo.)

GIAMBIAGI, F. et al. Diagnóstico da previdência social no Brasil: o que foi feito e o que falta reformar? Texto para Discussão, Rio de Janeiro: IPEA, n. 1.050, 44 p., 2004.

HOFFMANN, R. A subdeclaração dos rendimentos. São Paulo em Perspectiva, v. 2, n. 1, p. 50-54, jan./mar. 1988.

—. Desigualdade e pobreza no Brasil no período 1979-90. Revista Brasileira de Economia, v. 49, n. 2, p. 277-294, abr./jun. 1995.

. Desigualdade no Brasil: a contribuição das aposentadorias. www.eco.unicamp.br/projetos/rurbano.html. (17 out. 2002)

. Distribuição de renda: medidas de desigualdade e pobreza. São Paulo: EDUSP, 1998. $275 \mathrm{p}$.

—. Distribuição da renda no Brasil, em 1980, por unidades da federação. Revista de Economia Política, v. 3, n. 1, p. 31-41, jan./mar. 1983.

HOFFMANN, R.; DUARTE, J. C. A distribuição da renda no Brasil. Revista de Administração de Empresas, v. 12, n. 2, p. 46-66, abr./jun. 1972.

HOFFMANN, R.; KAGEYAMA, A. A. Distribuição da renda no Brasil, entre famílias e entre pessoas, em 1970 e 1980. Estudos Econômicos, v. 16, n. 1, p. 25-51, jan./abr. 1986.

INSTITUTO BRASILEIRO DE GEOGRAFIA E ESTATÍSTICA. Pesquisa Nacional por Amostra de Domicílios (compact disc). Rio de Janeiro, 1998, 1999, 2001, 2002 e 2003.

. Sintese de indicadores sociais 2003. Disponível em www.ibge.gov.br. Acesso em 13 jul. 2004. 
LACERDA, A. C. Distribuição de renda no Brasil nos anos 80. Revista de Economia Política, v. 14, n. 3, p. 134-140, jun./set. 1994.

MARIANO, J. L.; LIMA, R. C. A desigualdade da renda rural no Nordeste: análise da desagregação do coeficiente de Gini e da sensibilidade do índice de bem-estar de Sen. Análise Econômica, v. 16, n. 29, p. 103-118, mar. 1998.

MARQUES, R. M. A proteção social e o mundo do trabalho. São Paulo: Bienal, 1997.

MEDEIROS, M. Uma introdução às representações gráficas da desigualdade de renda. Rio de Janeiro: IPEA, 2006.

NEDER, H. D. Os efeitos das atividades não-agrícolas na distribuição de renda no meio rural (compact disc). In: CONGRESSO BRASILEIRO DE ECONOMIA E SOCIOLOGIA RURAL, 39, Recife, 2001. Anais. Brasília: Sober, 2001.

OliveIRA, M. A. (Org.). Reforma do Estado e políticas de emprego no Brasil. Campinas: Unicamp, 1998.

ORNÉLAS, W. O novo modelo previdenciário brasileiro: uma fase de transição. http://www.previdenciasocial.gov.br/07_08.htm (20 maio 2002).

ORNÉLAS, W.; VIEIRA, S. P. Novo rumo para a previdência brasileira. http://www.previdenciasocial.gov.br/07_09.htm (13 jun. 2002).

PYATT, G.; CHEN, C.; FEI, J. The distribution of income by factor components. The Quarterly Journal of Economics, v. 95, n. 3, p. 451-473, nov. 1980.

RAMOS, L; BRITTO, M. O funcionamento do mercado de trabalho metropolitano brasileiro no período 1991-2002: tendências, fatos estilizados e mudanças estruturais. Rio de Janeiro: IPEA, 2004.

RAMOS, L.; REIS, J. G. A. Emprego no Brasil nos anos 90. Rio de Janeiro: IPEA, 1997.

ROMÃO, M. C. Distribuição de renda, pobreza e desigualdades regionais no Brasil. In: Distribuição de renda no Brasil. Organização IERJ (José Márcio Camargo, Fábio Giambiagi). Rio de Janeiro: Paz e Terra, 1991. 237 p.

SCHWARZER, H. Paradigmas de previdência social rural: um panorama da experiência internacional. Brasília: IPEA, 2000.

SHORROCKS, A. F. Inequality decomposition by factor components. Econometria, v. 50, n. 1, p. 193-211, jan. 1982.

SINGER, P. Globalização e desemprego: diagnóstico e alternativas. São Paulo: Contexto, 1999.

SOUZA, S. C. I. A qualificação do trabalhador e a política pública de emprego e trabalho. (Tese de Doutorado), Pontifícia Universidade Católica de São Paulo, 2002.

STEPHANES, R. Reforma da previdência sem segredos. 2. ed. Rio de Janeiro: Record, 1999. $244 \mathrm{p}$.

VALLE, B. Políticas de mercado de trabalho no Brasil: a experiência do Proger. In: OLIVEIRA, M. A. (Org.). Reforma do Estado e políticas de emprego no Brasil. Campinas: Unicamp, 1998. 